\title{
Fernando Pessoa leitor de Schopenhauer e o problema do livre-arbítrio
}

\author{
Fernando Pessoa reader of Schopenhauer and the problem of free-will
}

\author{
Nuno Filipe Gonçalves Nunes Ribeiro*
}

\section{Cláudia Franco Souza}

Resumo: O presente artigo visa elucidar as relações entre Fernando Pessoa, Schopenhauer e a questão do livre arbítrio, tendo por base a leitura que o autor português fez da obra schopenhaueriana. Com efeito, ao longo dos escritos de Pessoa encontramos múltiplos testemunhos da leitura que o poeta e pensador português fez do pensamento schopenhaueriano. Um importante indício para o estudo da reapropriação pessoana do pensamento de Schopenhauer constata-se, desde logo, na Biblioteca Particular de Fernando Pessoa, onde encontramos uma tradução francesa do texto Über die Freiheit des menschlichen Willens [Sobre a liberdade da vontade] de Schopenhauer. A leitura deste livro viria a ocasionar a produção de uma multiplicidade de escritos filosóficos que Fernando Pessoa atribui a duas das suas personalidades literárias fictícias inglesas do universo pré-heteronímico: Charles Robert Anon e Alexander Search. Assim, tendo por base todos estes indícios, pretendemos mostrar o impacto da leitura de Schopenhauer no universo literário pessoano.

Palavras-chave: Fernando Pessoa; Schopenhauer; Livre-arbítrio; Pré-heterônimos

Abstract: This article aims to elucidate the relation between Fernando Pessoa, Schopenhauer and the problem of free-will, based on the reading that the Portuguese author made of the Schopenhauerian work. Indeed, throughout Pessoa's writings one finds multiple testimonies of the reading that the Portuguese poet and thinker made of Schopenhauerian thought. An important indication for the study of Pessoa's reappropriation of Schopenhauer's thought is found in Fernando Pessoa's Private Library, where one finds a French translation of Über die Freiheit des menschlichen Willens. The reading of this book would lead to the production of a multiplicity of philosophical writings that Fernando Pessoa attributes to two of his English fictitious literary personalities from the pre-heteronymic universe: Charles Robert Anon and Alexander Search. Thus, based on all these indications, we intend to show the impact of Schopenhauer's reading on Pessoa's literary universe.

Keywords: Fernando Pessoa; Schopenhauer; Free-Will; Pre-heteronyms

\footnotetext{
* Pós-doutorando do Instituto de Estudos de Literatura e Tradição, Universidade Nova de Lisboa, Lisboa, PT. E-mail: nuno.f.ribeiro@sapo.pt ORCID: https://orcid.org/0000-0002-2118-8845
}

\footnotetext{
* Investigadora associada do Centro de Filosofia da Universidade de Lisboa, Lisboa, PT. E-mail: claudiasouzzza@hotmail.com ORCID: https://orcid.org/0000-0002-5651-2860
} 
A obra de Fernando Pessoa constitui-se como um dos momentos fundamentais da recepção do pensamento de Arthur Schopenhauer na cultura portuguesa. Ao longo dos escritos de Pessoa encontramos múltiplos testemunhos da leitura que o poeta e pensador português fez do pensamento schopenhaueriano. Um importante indício para o estudo da reapropriação pessoana do pensamento de Schopenhauer encontra-se, desde logo, na Biblioteca Particular de Fernando Pessoa, onde existe um livro em intitulado Essai sur le Libre Arbitre ${ }^{1}$, correspondente a uma tradução francesa do texto Ueber die Freiheit des menschlichen Willens [Sobre a liberdade da vontade] de Schopenhauer realizada por Salomon Reinach, numa edição do ano de 1903. Logo na folha de rosto desse livro constata-se a assinatura de "F. A. N. Pessôa” com a data de "April, 1906" [“Abril, 1906"]2. Esses dados constituem-se como elementos relevantes porque nos indicam o mês e o ano no qual o pensador português terá adquirido e tido um primeiro contato com esse livro de Schopenhauer. A leitura do Essai sur le Libre Arbitre viria, porém, a ocorrer somente alguns meses mais tarde, em Agosto de 1906, conforme se pode verificar numa nota de um caderno de leituras com a assinatura de "F. A. N. Pessôa”, onde encontramos a seguinte indicação: " 5 de Agosto: Domingo. Schopenhauer: 'Essai sur le Libre Arbitre”3.

[BNP/E3, 144N - 16: pormenor do fac-símile $\left.{ }^{4}\right]$

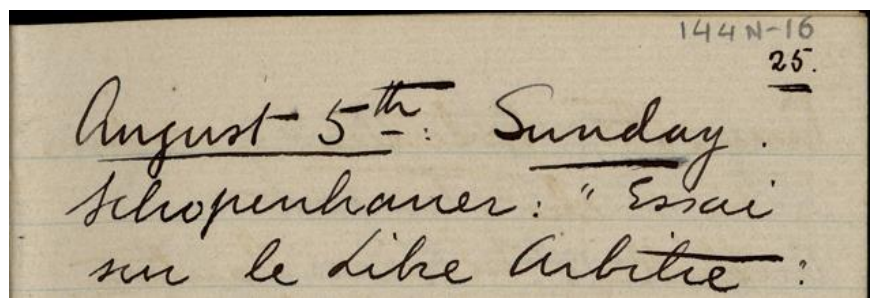

No entanto, para além da assinatura de Fernando Pessoa encontramos, no contexto da criação literária pessoana, a assinatura de outras personalidades criadas pelo poeta e pensador português que viriam a assumir a tarefa de ler e comentar o pensamento de Arthur Schopenhauer. Essas personalidades correspondem ao nome de dois préheterônimos pessoanos: Charles Robert Anon e Alexander Search.

Os pré-heterônimos são personalidades literárias pessoanas anteriores ao surgimento dos heterônimos. Com efeito, no documento que ficou conhecido como carta

1 Cf.: CFP, 1-135. (A sigla “CFP” [“Casa Fernando Pessoa”] refere-se à Biblioteca Particular de Fernando Pessoa, que actualmente se encontra abrigada pela Casa Fernando Pessoa. A numeração corresponde à catalogação dos livros presente na Biblioteca Particular de Fernando Pessoa.)

${ }^{2}$ CFP, 1-135, folha de rosto.

${ }^{3}$ RIBEIRO, SOUZA (eds.), Fernando Pessoa, Schopenhauer \& Nietzsche, 70. Tradução nossa. Traduzimos os textos que se encontram originalmente em outras línguas, salvo nos casos em que indicamos a referência bibliográfica de uma tradução.

${ }^{4}$ A sigla "BNP/E3" refere-se à catalogação do Espólio de Fernando Pessoa - Espólio 3 [E3] - que se encontra atualmente na Biblioteca Nacional de Portugal [BNP]. A numeração - após a sigla "BNP/E3" - corresponde ao número de catalogação do documento no Espólio de Fernando Pessoa. 
sobre a gênese dos heterônimos, escrita a 13 de Janeiro de 1935 e dirigida a Adolfo Casais Monteiro, Fernando Pessoa apresenta o mítico dia 8 de Março de 1914 como a data do surgimento dos seus três heterônimos (Alberto Caeiro, Ricardo Reis e Álvaro de Campos). A primeira aparição pública da heteronímia ocorre em 1915 com a publicação do "Opiário" e da "Ode Triunfal” de Álvaro de Campos no primeiro número da revista Orpheu. Contudo, existe todo um trabalho de criação pré-heteronímica que antecede o surgimento dos heterônimos. Na carta de sobre a gênese dos heterônimos, Fernando Pessoa deixa-nos a seguinte indicação a esse respeito:

Desde criança tive a tendência para criar em meu torno um mundo fictício, de me cercar de amigos e conhecidos que nunca existiram. (Não sei, bem entendido, se realmente não existiram, ou se sou eu que não existo. Nestas coisas, como em todas, não devemos ser dogmáticos). Desde que me conheço como sendo aquilo a que chamo eu, me lembro de precisar mentalmente, em figura, movimentos, carácter e história, várias figuras irreais que eram para mim tão visíveis e minhas como as coisas daquilo a que chamamos, porventura abusivamente, a vida real. Esta tendência, que me vem desde que me lembro de ser um eu, tem-me acompanhado sempre, mudando um pouco o tipo de música com que me encanta, mas não alterando nunca a sua maneira de encantar ${ }^{5}$.

No que respeita a Charles Robert Anon, encontramos numa lista de leituras presente num caderno, assinado por esse pré-heterônimo e datável de 1906, a referência a quatro títulos - em francês e em inglês - de obras de Schopenhauer:

Schopenhauer: "Le Monde comme Volonté et Représentation”.

\section{Shopenhaver': 'Le Inonde comme Volonté et Représentation.}

$[\ldots]$

Schopenhauer: "The Fourfold Root of the Principle of Sufficient Reason.”

Schopenhauer: "On the Will in Nature".

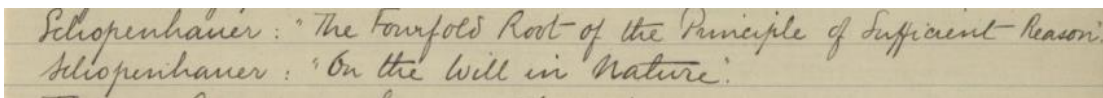

$[\ldots]$

${ }^{5}$ PESSOA, Correspondência - 1923-1935, 341 
Schopenhauer: "Essai sur le Libre Arbitre"6.

\section{Schonenhaner: "Esai sur le dibu Arbihe."}

Relativamente a Alexander Search, é possível constatar indícios do interesse pela leitura da filosofia schopenhaueriana num caderno com a assinatura dessa personalidade, datado de "September, 1906" ["Setembro, 1906”] e com a indicação "Philosophy, ect." ["Filosofia, ect."] escritos de Schopenhauer:

1. Schopenhauer: "Le Monde comme Idée et Représentation". (3v.)

1. "Essai sur le Libre Arbitre."

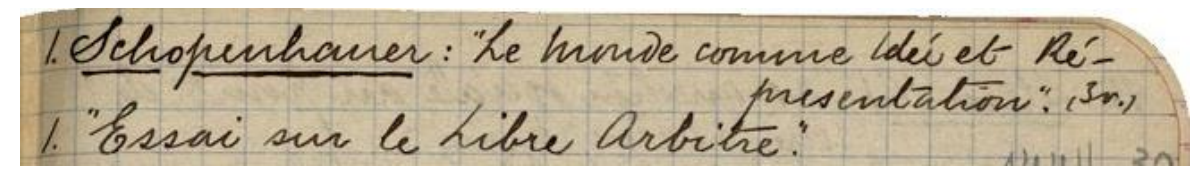

$[\ldots]$

1. "Le Fondement de la Morale"8.

\section{1. "Le Indenvent de la hovale."}

Não sabemos se Pessoa chegou efetivamente a ler todos os livros de Schopenhauer referidos nas listas de Charles Robert Anon e de Alexander Search. De fato, a única evidência da leitura direta de livros de Arthur Schopenhauer corresponde à tradução francesa intitulada Essai sur le Livre Arbitre, a qual viria a constituir-se como tema de debate, reapropriação e crítica ao longo dos escritos filosóficos pessoanos atribuídos tanto a Anon quanto a Search. Um importante indício a este respeito corresponde a um projeto filosófico, escrito em inglês com o título “On Free-Will” [“Sobre o Livre-Arbítrio"], atribuído por Fernando Pessoa ao pré-heterônimo Charles Robert Anon, conforme se pode ver no seguinte esboço que apresenta duas versões desse projeto:

Charles Robt. Anon.

C. R. Anon.

\footnotetext{
${ }^{6}$ RIBEIRO, SOUZA (eds.), Fernando Pessoa, Schopenhauer \& Nietzsche, 72-74. BNP/E3, 13A - 7-8 pormenores dos fac-símiles.

${ }^{7} \mathrm{BNP} / \mathrm{E} 3,144 \mathrm{H}$ - Contra-guarda.

${ }^{8}$ RIBEIRO, SOUZA (eds.), Fernando Pessoa, Schopenhauer \& Nietzsche, 76. BNP/E3, 144H - 30": pormenores dos fac-símiles.
} 
Sobre o Livre-Arbitrio

\section{Prefácio}

Parte $I$

1. História da Questão.

2. Argumentos pró e contra.

3. Novos Argumentos.

Parte II

4. Responsabilidade.

5. Consequências.

\section{Sobre o Livre-Arbitrio}

\section{Prefácio}

1. Definições.

2. História do Problema.

3. Argumentos pró e contra.

4. Novos Argumentos.

5. Sobre a Responsabilidade.

6. Consequências da inexistência do Livre-Arbítrio.

7. Conclusões. Caráter.

8. Índice de Capítulos e de Conteúdos9.

O interesse de Pessoa pela problemática do livre-arbítrio foi inicialmente impulsionado pela questão relativa à pena de morte. No diário de Charles Robert Anon lemos o seguinte trecho escrito a 12 de Abril de 1906, relativo à gênese do interesse por leituras relativas à temática do livre-arbítrio: "Planeei e comecei a escrever um trabalho em inglês contra a pena de morte, e, talvez, contra os maus-tratos nas prisões. Tenho de ler livros sobre o livre-arbítrio para poder atacar a pena de morte" ${ }^{10}$.

\footnotetext{
${ }^{9}$ PESSOA, Philosophical Essays: a critical edition, 27.

${ }^{10}$ PESSOA, Escritos Autobiográficos, Automáticos e de Reflexão Pessoal, 35.
} 
Dessa intenção de leituras relativas ao livre-arbítrio terá resultado a seguinte lista de livros, entre os quais se lê a referência à tradução francesa do Essai sur le Libre Arbitre de Schopenhauer:

\section{Bibliography.}

Fouillée (Alfred): "La Liberté et le déterminisme”, 2e edition, Paris, Alcan, 1884.

Schopenhauer: "Essai sur le libre arbitre", trad. Salomon Reinach, 9th ed. Paris, Alcan, 19...

Naville (E): "Le Libre Arbitre", Paris, Alcan, ${ }^{11}$.

Child (Thomas): "Root Principles in Rational and Spiritual Things." London, Speirs, 1905.

Kant: “Critique de la Raison Pratique” - Trad.

Lutherus: "De Servo Arbitrio."

Edwards (Jonathan): “On Free Will”.

Stuart Mill: “Examination of Sir Wm. Hamilton’s Philosophy.”

Renard: “L’Homme est-il libre?” - Paris, Alcan, 口

Secrétan: "Philosophie de la Liberté."

(Hartmann: Philosophie de L’Inconscient? ${ }^{12}$ )

Nos fragmentos relativos ao livre-arbítrio, Fernando Pessoa insiste na ideia do caráter ilusório do sentido desta noção, mobilizando para tal uma multiplicidade de conceitos presentes em Sobre a liberdade da vontade de Schopenhauer. Num excerto destinado ao ensaio Against the Death Penalty ${ }^{13}$ [Contra a Pena de Morte] de Pessoa - cuja temática, conforme assinalamos, se encontra na origem do interesse pela questão do livrearbítrio - o autor português afirma, desde logo, que "O livre-arbítrio é uma ilusão"14. A ideia de que o livre-arbítrio é uma ilusão viria a constituir um mote de toda a posterior produção pessoana relativa a esta problemática, conforme lemos, por exemplo, num fragmento destinado a "On Free-Will” de Charles Robert Anon:

A vacuidade da teoria do livre-arbítrio nunca foi suficientemente apresentada. Dos filósofos que lidaram com esse assunto, os idealistas e

\footnotetext{
${ }^{11}$ O símbolo " " serve para assinalar um espaço em branco no documento original, presente no Espólio de Fernando Pessoa.

${ }^{12}$ RIBEIRO, SOUZA (eds.), Fernando Pessoa, Schopenhauer \& Nietzsche, 82.

${ }^{13}$ Cf.: PESSOA, Philosophical Essays: a critical edition, 160-163.

${ }^{14}$ PESSOA, Philosophical Essays: a critical edition, 161.
} 
semi-idealistas viram claramente o problema, mas envolveram os seus pensamentos numa linguagem tão filosófica que o leitor fica sem uma ideia clara da natureza da discussão. Por outro lado, os cientistas, que não vêem nada claramente porque o seu talento consiste em observar - os cientistas, digo, contentam-se com a negação da teoria e com o blasfemar contra ela, sem a mínima ideia do que significa o livre-arbítrio ou do que ele não significa ${ }^{15}$.

O preconceito de que existe o livre-arbítrio, isto é, de que o livre-arbítrio não é uma ilusão, resulta, segundo Pessoa, da confusão entre os conceitos de liberdade física e de liberdade moral. Com efeito, lemos num excerto de um fragmento sobre o livre-arbítrio:

A ideia de livre-arbítrio tem, na minha opinião, a sua origem na aplicação ao mundo moral da ideia primitiva e natural de liberdade física. Esta aplicação, esta analogia é inconsciente; e é também falsa. É, repito, um daqueles erros inconscientes que fazemos, um daqueles falsos raciocínios aos quais tão frequente e naturalmente anuímos ${ }^{16}$.

A análise que Pessoa efetua da noção de livre-arbítrio como resultante da confusão entre liberdade física e liberdade moral encontra a sua fundamentação na leitura do “Capítulo I" do Essai sur le libre arbitre de Schopenhauer. De acordo com Schopenhauer a liberdade física consiste na simples ausência de obstáculos materiais. É isso que lemos na seguinte passagem do primeiro capítulo do Essai sur le libre arbitre, parcialmente sublinhada por Pessoa:

A liberdade física consiste na ausência de obstáculos materiais de toda a natureza. É neste sentido que dizemos: um céu livre (sem nuvens), um horizonte livre, o ar livre (o grande ar), a electricidade livre, o livre curso de um rio (logo que não seja travado pelas montanhas ou por diques), etc ${ }^{17} \ldots$

$\mathrm{Na}$ sequência do texto acima referido Pessoa cita justamente esta noção de liberdade física de Schopenhauer dizendo: "Schopenhauer indicou que a primitiva noção de liberdade consiste na "ausência de obstáculos", uma noção puramente física"18.

Por outro lado, a liberdade moral - que, segundo a filosofia schopenhaueriana, constitui aquilo a que propriamente se chama livre-arbítrio - existiria se a vontade pudesse perante motivos diversos escolher livremente querer ou não querer sem ser coagida, o que Schopenhauer mostra não ser possível. Estas definições apresentadas no Essai sur le libre arbitre de Schopenhauer permitem-nos compreender o sentido da crítica de Pessoa à

\footnotetext{
${ }^{15}$ PESSOA, Philosophical Essays: a critical edition, 46.

${ }^{16}$ PESSOA, Philosophical Essays: a critical edition, 62.

${ }^{17}$ CFP, 1-135, 2.

${ }^{18}$ PESSOA, Philosophical Essays: a critical edition, 62.
} 
noção de livre-arbítrio. Aplicar ao mundo moral a noção de liberdade física significa conceber a atividade da vontade à semelhança da noção da liberdade física. A noção de liberdade física afirma, como vimos, que são livres aqueles entes que não encontram qualquer obstáculo para a sua ação. Assim, a liberdade moral consistiria, por analogia com a liberdade física, na capacidade de a vontade agir por si própria sem qualquer necessidade externa ou interna. Deste modo, haveria um ato livre sempre que a vontade agisse por si só sem qualquer coação ou impedimento. Contudo, a ideia de que a vontade, à semelhança da noção de liberdade física, poderia agir por si própria sem qualquer entrave externo ou interno resulta, segundo Pessoa, de uma falsa analogia que estaria na origem da noção de livre-arbítrio, o que conduz o autor português à ideia de que o livre-arbítrio é uma ilusão.

Da leitura que Pessoa fez do Essai sur le libre arbitre de Schopenhauer, em Agosto de 1906, resultaram diversas referências que se estendem para além dos fragmentos e projetos destinados a "On Free-Will” de Charles Robert Anon. Um claro exemplo disso corresponde a um texto, assinado pelo pré-heterônimo Alexander Search, com o título "Essay on the Idea of Cause"19 ["Ensaio sobre a Ideia de Causa"] e que é um dos que mais proximamente discute as teses e os conceitos defendidos no Essai sur le libre arbitre. O "Essay on the Idea of Cause", do qual nos resta apenas um excerto em inglês, constitui-se como uma discussão sobre os diversos sentidos da noção de causalidade apresentados por Schopenhauer. Com efeito, lemos logo no início desse texto: "Schopenhauer dividiu a ideia de Causa em 3 outras ideias, a saber: Causação, excitação e motivação”20.

De acordo com o ensaio do autor alemão, cujo exemplar da edição francesa está conservado na Biblioteca Particular de Fernando Pessoa, a ideia de causalidade constitui a forma geral do entendimento e a condição de possibilidade da percepção do mundo. Lemos, nesse sentido, a seguinte passagem do Essai sur le libre arbitre:

A forma mais geral e mais essencial do nosso entendimento é o princípio de causalidade: é mesmo graças a esse princípio, sempre presente ao nosso espírito, que o espectáculo do mundo real se pode abrir ao nosso olhar como um conjunto harmonioso, porque nos faz conceber imediatamente como efeitos as afeções e modificações que sobrevêm aos órgãos dos nossos sentidos ${ }^{21}$.

Partindo desta caracterização geral, Schopenhauer distingue os três tipos de causalidade referidos e explicitados por Pessoa no "Essay on the Idea of Cause": a causação, a excitação e a motivação. A causação é o tipo de causalidade que ocorre no domínio dos seres inorgânicos. Aquilo que caracteriza a causação é a obediência à segunda e terceira leis de Newton, isto é, respectivamente: 1) ao princípio segundo o qual o grau de

\footnotetext{
${ }^{19}$ Cf.: PESSOA, Philosophical Essays: a critical edition, 92-96.

${ }^{20}$ PESSOA, Philosophical Essays: a critical edition, 92.

${ }^{21}$ CFP, 1 - 135, 50-51.
} 
intensidade de um efeito é proporcional ao grau de intensidade de uma causa; 2) ao princípio de que existe uma proporcionalidade entre a ação e a reação. A excitação, por seu turno, ocorre tipicamente no domínio dos seres vegetativos e é caracterizada pela inexistência de uma proporcionalidade entre a ação e a reação e entre a intensidade da causa e do efeito. Finalmente, a motivação corresponde ao tipo de causalidade que age por meio do entendimento. A motivação, que segundo Schopenhauer caracteriza os entes do domínio animal, surge quando um determinado ente tem necessidades mais complexas que não podem ser satisfeitas apenas por meio da excitação.

A discussão inicial do "Essay on the Idea of Cause" relativa às três acepções da ideia de causa foi certamente impulsionada pelo seguinte trecho do Essai sur le libre arbritre e pelas páginas que se lhe seguem:

O princípio de causalidade, que rege todas as modificações dos seres, apresenta-se sob três aspectos, correspondentes à tripla divisão dos corpos em corpos inorgânicos, em plantas e em animais; a saber: 1ํㅡ A Causação, no sentido mais estrito da palavra; $2^{\circ}$ a Excitação (Reiz); $3^{\circ}$ por fim a Motivação. Torna-se evidente que sob estas três formas diferentes, o princípio de causalidade conserva o seu valor à priori, e que a necessidade da ligação causal subsiste em todo o seu rigor ${ }^{22}$.

A leitura que Pessoa faz de Schopenhauer no "Essay on the Idea of Cause" tem, por conseguinte, dois momentos: primeiro, o da elucidação das várias acepções da ideia de Causa, presentes no texto de Schopenhauer; segundo, a crítica da ideia schopenhaueriana de causa. A crítica da ideia de causa, realizada por Pessoa neste ensaio, incide principalmente sobre a primeira acepção da noção schopenhaueriana de causalidade, isto é, sobre a noção de causação. A crítica à noção de causação tem por base a desconstrução dos pressupostos subjacentes à noção de lei causal, ou seja, ao princípio de acordo com o qual a aplicação das mesmas causas às mesmas coisas nas mesmas circunstâncias produz os mesmos efeitos. Com efeito, diz-nos Pessoa:

Podemos com bastante justificação afirmar que se a mesma quantidade de calor for três vezes aplicada à mesma barra de ferro, irá muito certamente produzir todas as vezes a mesma expansão. Mas, tanto quanto sabemos, o mesmo fato nunca é repetido exactamente como aconteceu, nem existem, assim cremos, duas coisas iguais em todo o universo. A barra de ferro que usámos já não é a barra de ferro que agora usamos, pela terceira vez. A sua radioatividade é, de fato, infinitesimal; contudo, existe e um experimento não pode ser o mesmo. A barra de ferro é a mesma e não é a mesma. "O ser é nada", disse Heraclito, "e o devir é tudo" 23.

\footnotetext{
${ }^{22}$ CFP, 1 - 135, 56.

${ }^{23}$ PESSOA, Philosophical Essays: a critical edition, 93.
} 
De acordo com este trecho, a crítica às noções de causação e de lei causal tem implícita a ideia de que não existem dois fatos iguais. Com efeito, a admissão de uma proporcionalidade entre a ação e a reação e entre a intensidade da causa e a intensidade do efeito tem subjacente o pressuposto de que a aplicação das mesmas causas às mesmas coisas nas mesmas circunstâncias produz os mesmos efeitos. No entanto, aquilo que o "Essay on the Idea of Cause" contesta é o pressuposto de que se possam verificar duas ou mais circunstâncias iguais. De fato, tudo no mundo é transformação, isto é, devir. Sendo tudo devir, todas as circunstâncias estão em permanente modificação originando continuamente novas circunstâncias ou acontecimentos. Deste modo, sendo tudo devir e transformação não existem duas circunstâncias inteiramente iguais. Logo, o princípio da lei causal segundo o qual as mesmas causas nas mesmas circunstâncias produzem os mesmos efeitos é um princípio ineficaz, uma vez que o pressuposto em que esse princípio assenta não apresenta as condições necessárias para que se verifique aquilo que postula.

Assim, partindo do princípio que não existem duas circunstâncias iguais e de que tudo é devir, o "Essay on the Idea of Cause" substitui a noção de nexo de causalidade pela noção de transmissão de movimento. Mostrando-se a ideia de lei causal ineficaz e sendo tudo transformação, aquilo que existe é transmissão de movimento de uma coisa para outra coisa. É isso que lemos no seguinte trecho:

Em primeiro lugar devemos, então, fazer esta objeção: o que Schopenhauer chama causação não tem nada de causa. A transmissão de calor a uma barra de ferro que resulta na separação das moléculas de ferro, não consiste numa relação de causa e efeito. É apenas a transmissão de movimento; não é diferente de uma bola de bilhar que bate em outra e pára, cedendo à outra o seu movimento. Mas se eu atirar uma pedra com igual força em dois momentos diferentes - uma mera hipótese, é claro - ainda que em diferentes ocasiões, uma contra uma árvore, outra num campo aberto, é obvio que mesmo aqui não se coloca a questão da causação. Independentemente de serem diversos, o movimento destas duas pedras, no que respeita à sua quantidade, é rigorosamente igual; só pode ser assim, uma vez que é, em ambos os casos, o produto de uma força igual. E o movimento deve forçosamente ser o produto e a continuação de outro movimento e este o resultado de outro e, deste modo, todas as forças e movimentos do universo estão ligados. Aquilo a que se chama causação não é senão a mudança de um movimento para outro, ou de uma forma de movimento para outra forma, ou a mudança de meios no mesmo movimento ${ }^{24}$.

Este texto deixa claro em que sentido se deve entender a crítica realizada no "Essay on the Idea of Cause" à noção schopenhaueriana de causalidade. Aquilo que existe é

\footnotetext{
${ }^{24}$ PESSOA, Philosophical Essays: a critical edition, 94-95.
} 
apenas movimento. Logo, as relações entre os diversos corpos obedecem não a um nexo ou a uma lei causal, mas à simples transmissão contínua de movimentos que transitam dos corpos uns para os outros. A causação é uma ilusão que se gera a partir da transmissão de movimento resultante do contato dos corpos uns com os outros. A ideia de causação é, por conseguinte, uma ideia falsa derivada da transferência de movimento.

Todos os elementos que temos vindo a elucidar permitem-nos compreender o impacto da leitura do pensamento schopenhaueriano nos escritos de dois pré-heterônimos de Fernando Pessoa, possibilitando, dessa forma, compreender a complexa rede interpretativa pessoana, que abrange diferentes personalidades, a quem o autor português atribui diferentes leituras e encarrega de assinar projetos diversos com pontos de vista diferentes sobre as questões ligadas à temática do livre-arbítrio na filosofia de Schopenhauer.

\section{Referências}

PESSOA, F. Correspondência (1923-1935). Edição de Manuela Parreira da Silva. Lisboa: Assírio \& Alvim, 1999.

PESSOA, F. Escritos Autobiográficos, Automáticos e de Reflexão Pessoal. Edição de Richard Zenith. Lisboa: Assírio \& Alvim, 2003.

PESSOA, F. Philosophical Essays: a critical edition. Edition, notes and introduction by Nuno Ribeiro. Afterword by Paulo Borges. New York: Contra Mundum Press, 2012.

RIBEIRO, N., SOUZA, C. (eds.). Fernando Pessoa, Schopenhauer \& Nietzsche. Lisboa: Apenas Livros, 2017.

SCHOPENHAUER, A. Essai sur le libre arbitre. Traduit en français pour la première fois et annoté par Salomon Reinach. Paris : Félix Alcan, 1903. [CFP, 1-135] 